\title{
EFFECTS OF GRAINS SIZE AND SANDBLASTING DURATION TO THE SURFACE HARDNESS OF THE CASTING PRODUCT OF USED PROPELLER
}

\author{
Nurfi Ahmadi \\ Program Studi Teknik Mesin \\ Sekolah Tinggi Teknologi Adisutjipto \\ Jl. Janti Blok R Komplek Lanud Adisutjipto Yogyakarta 55198 \\ E-Mail : nurfi.ahmadi@yahoo.com
}

\begin{abstract}
This research carried out the sandblasting process on used aluminum propeller castings with variations in sand grains: 40 mesh, 60 mesh, and 80 mesh with variations of 30 seconds, 60 seconds and 90 seconds. The size of the grain and the varying time result in different surface hardness. The biggest hardness on sandblasting with a grain size of 40 mesh time of 90 seconds is $39.8 \mathrm{VHN}, 60$ mesh time of 30 seconds is $38.6 \mathrm{VHN}, 80$ mesh time of 30 seconds is $37.1 \mathrm{VHN}$, from the photo macro the abrasion of the largest surface material occurs at grain size 40 mesh.
\end{abstract}

Keywords: Sandblasting, hardness, photo macro.

\section{Pendahuluan}

Perkembangan industri manufaktur yang terus meningkat menuntut ketersediaan material dasar yang salah satu solusinya adalah dengan melakukan daur ulang material bekas, namun proses daur ulang yang dilakukan beberapa kali akan menurunkan kekuatan tarik dan kekerasan [1], proses remelting mempengaruhi sifat mekanis pada paduan aluminium yaitu penurunan kekerasan dan kekuatan fatik.

Dalam upaya peningkatan sifat permukaan material dapat dilakukan beberapa metode yang telah berhasil dilaksanakan antara lain: Surface Mechanichal Attrition Treatment (SMAT) pada baja tahan karat 316L [2], Shotpeening pada baja tahan karat 316L [3,6] dan sandblasting pada material baja [4,5]. Pada penelitian ini akan digunakan metode sandblasting untuk meningkatkan sifat permukaan material. Sandblasting adalah suatu proses perlakuan permukaan logam dengan jalan menembakkan butiran pasir ke permukaan logam pada tekanan tinggi. Hal-hal yang menentukan hasil proses sandblasting antara lain adalah ukuran butiran pasir dan waktu sandblasting. Sandblasting diharapkan dapat merubah struktur permukaan material yang terbentuk menjadi lapisan struktur berukuran nano sehingga dapat meningkatkan sifat-sifat mekanik material. Hasil pengujian kekerasan menunjukkan penambahan kekerasan sebesar 13,625\% pada material aluminium 6061 yang disandblasting [4], durasi dan ukuran butir sandblasting mempengaruhi nilai kekasaran permukaan [5]. Pada aluminium alloy seri 7075 T651, shotpeening dengan variable waktu selama 5 menit, 10 menit dan 15 menit kekerasan vickers menunjukkan penambahan kekerasan sebesar 61,453\% pada material yang di shootpeening selama 15 menit [6].

Dari uraian diatas proses sandblasting diharapkan dapat meningkatkan properties dari bahan hasil cor material bekas. Pada penelitian ini sandblasting dilakukan dengan memvariasikan waktu proses sandblasting dan ukuran butir pasir yang digunakan.

\section{Metodologi Penelitian}

Bahan yang digunakan adalah aluminium dari propeller bekas di cor dengan menggunakan cetakan logam, kemudian hasil coran di potong dengan ukuran yang $20 \mathrm{~mm} \mathrm{X}$ 
$20 \mathrm{~mm}$ dengan ketebalan $6 \mathrm{~mm}$. Selanjutnya benda uji di bersihkan dan dihaluskan menggunakan amplas halus agar dapat maksimal ketika di lakukan proses selanjutnya. Pada proses sandblasting ini terbagi menjadi beberapa variasi yaitu perbedaan besar butiran pasir yang di semprot kan dan lama penyemprotan. Dalam penelitian ini menggunakan 3 ukuran besar ukuran butiran pasir yaitu 40, 60 dan 80 mesh, dengan lama penyemprotan 30, 60 dan 90 detik, kemudian hasil coran dan hasil proses sandblasting diuji kekerasannya pada permukaan melintang.

\section{Hasil dan Pembahasan}

\subsection{Karakteristik Raw Material}

Pengujian komposisi, uji komposisi dilakukan untuk mengetahui kandungan yang terdapat dalam material yang akan dilakukan sandblasting. Hasil pengujian komposisi disajikan pada Tabel 1.

Tabel 1. Kandungan dalam material uji

\begin{tabular}{|c|c|c|}
\hline \multirow{2}{*}{ UNSUR } & \multicolumn{2}{|c|}{ SAMPEL UJI } \\
\cline { 2 - 3 } & 17 IS246 (\%) & Deviasi \\
\hline $\mathrm{Al}$ & 98,27 & 0,1473 \\
\hline $\mathrm{Si}$ & 0,313 & 0,0421 \\
\hline $\mathrm{Fu}$ & 0,849 & 0,107 \\
\hline $\mathrm{Mn}$ & 0,168 & 0,0000 \\
\hline $\mathrm{Mg}$ & $<0,0200$ & $<0,0000$ \\
\hline $\mathrm{Cr}$ & $<0,0500$ & $<0,0000$ \\
\hline $\mathrm{Ni}$ & $<0,0150$ & $<0,0000$ \\
\hline $\mathrm{Zn}$ & $<0,0100$ & $<0,0000$ \\
\hline $\mathrm{Sn}$ & 0,163 & $<0,0000$ \\
\hline $\mathrm{Ti}$ & $<0,0100$ & 0,0176 \\
\hline $\mathrm{Pb}$ & $<0,0300$ & $<0,0000$ \\
\hline $\mathrm{Be}$ & 0,0001 & $<0,0000$ \\
\hline $\mathrm{Ca}$ & 0,0141 & 0,0000 \\
\hline $\mathrm{Sr}$ & $<0,0005$ & 0,0025 \\
\hline $\mathrm{V}$ & 0,0195 & $<0,0000$ \\
\hline $\mathrm{Zr}$ & 0,0516 & 0,0041 \\
\hline & & 0,0353 \\
\hline
\end{tabular}

Nilai kekerasan raw material, pada Tabel 2 disajikan hasil pengujian kekerasan vickers pada raw material pada permukaan melintang.

Tabel 2. Hasil uji kekerasan penampang melintang raw material

\begin{tabular}{|c|c|c|c|c|c|}
\hline No & $\begin{array}{c}\text { Jarak dari tepi } \\
(\mu \mathrm{m})\end{array}$ & $\begin{array}{c}\mathrm{d} 1 \\
(\mu \mathrm{m})\end{array}$ & $\begin{array}{c}\mathrm{d} 2 \\
(\mu \mathrm{m})\end{array}$ & $\begin{array}{c}\mathrm{d} \text { rata-rata } \\
(\mu \mathrm{m})\end{array}$ & $\begin{array}{c}\text { Kekerasan } \\
(\mathrm{VHN})\end{array}$ \\
\hline 1 & 50 & 55.0 & 52.0 & 53.50 & 32.4 \\
\hline 2 & 100 & 53.0 & 52.0 & 52.50 & 33.6 \\
\hline 3 & 150 & 53.0 & 53.0 & 53.0 & 33.0 \\
\hline
\end{tabular}

Dari hasil pengujian didapatkan nilai kekersan vickers rata-rata adalah sebesar 33 VHN. 


\subsection{Kekerasan Material}

Uji kekerasan material dilakukan pada permukaan melintang benda uji setelah dilakukan sandblasting dengan berbagai variasi ukuran butir dan waktu sandblasting sebagai berikut:

\section{Ukuran butir 40 mesh dengan durasi waktu 30,60,90 detik.}

Pengujian kekerasan dilakukan pada permukaan melintang denngan jarak 50, 100,150 $\mu \mathrm{m}$ dari permukaan benda uji. Pada ukuran butir 40 mesh didapatkan hasil seperti pada gambar 1 berikut:

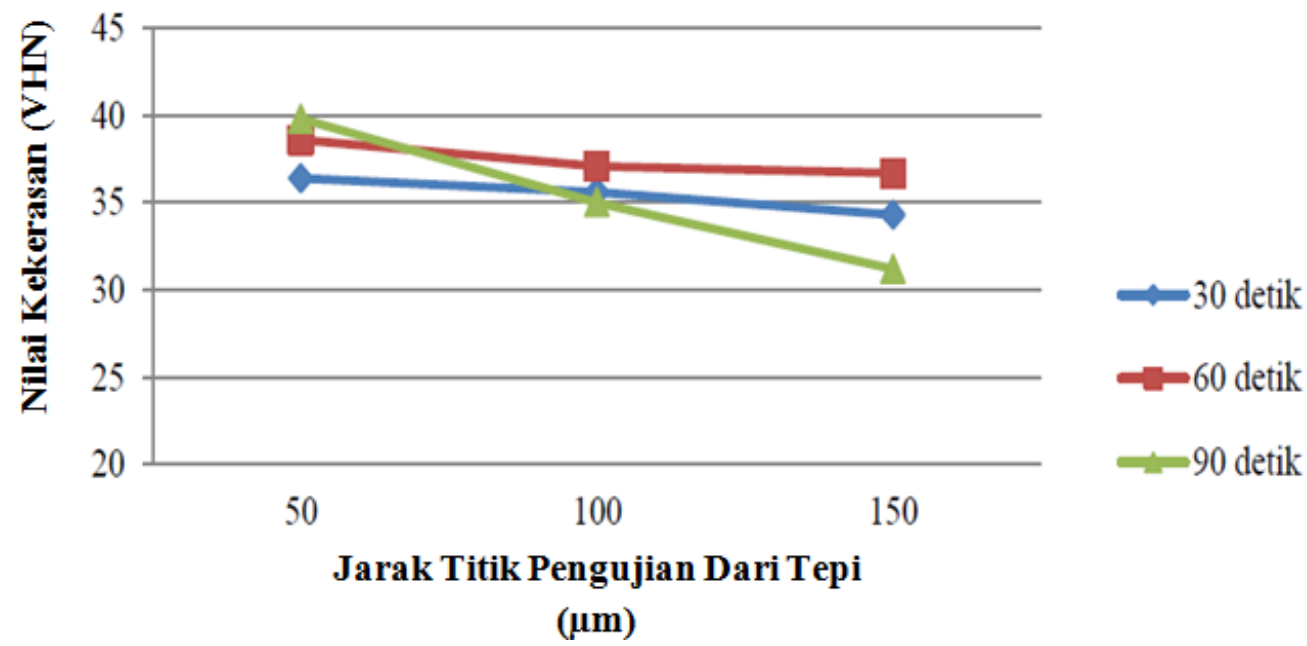

Gambar 1. Kekerasan Vickers pada variasi durasi waktu 30,60,90 detik dengan ukuran butir 40 mesh

Pada Gambar 1. dapat diamati kekerasan tertinggi didapatkan pada durasi waktu 90 menit pada posisi terdekat $(50 \mu \mathrm{m})$ dengan permukaan yaitu sebesar 39,8 VHN atau mengalami kenaikan sebesar 20,6\%, seiring dengan bertambahnya jarak dari permukaan kekerasan material juga mengalami penurunan yang signifikan, hal ini menunjukkan bahwa daerah yang dipengaruhi oleh proses sandblasting terbesar ada pada permukaan material yang mengalami kontak langsung dengan butiran.

Ukuran butir 60 mesh dengan durasi waktu 30,60,90 detik.

Pengujian kekerasan dilakukan pada permukaan melintang dengan jarak 50, 100,150 $\mu \mathrm{m}$ dari permukaan benda uji. Pada ukuran butir 60 mesh didapatkan hasil seperti pada Gambar 2. berikut:

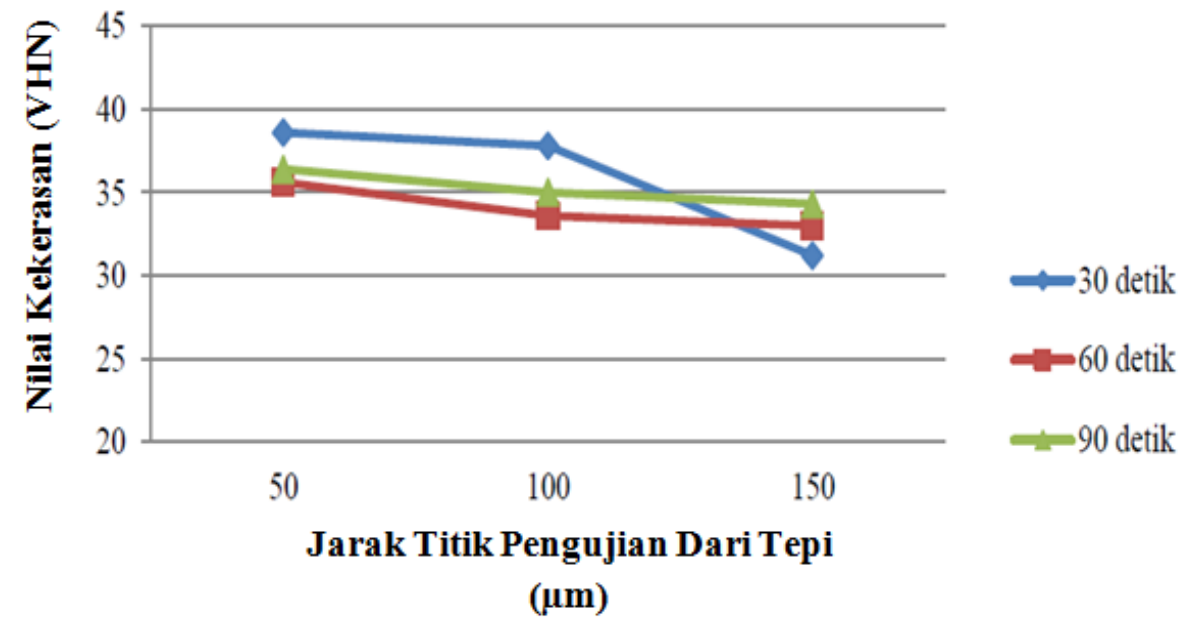

Gambar 2. Kekerasan Vickers pada variasi durasi waktu 30,60,90 detik dengan ukuran butir 60 mesh 
Kekerasan pada permukaan material hasil sandblasting dengan ukuran 60 mesh dengan variasi waktu 30,60,90 detik disajikan pada Gambar 2. Kekerasan tertinggi diperoleh pada durasi 30 detik yaitu sebesar 38,6 VHN atau mengalami kenaikan sebesa 16,9\%, pada jarak $50 \mu \mathrm{m}$ hingga jarak $100 \mu \mathrm{m}$ grafik menunjukkan penurunan yang relatif datar walaupun pada jarak $100 \mu \mathrm{m}$ hingga $150 \mu \mathrm{m}$ mengalami penurunan kekerasan yang cukup signifikan, hal ini menunjukkan untuk ukuran butir 60 mesh daerah yang dipengaruhi oleh sandblasting lebih dalam dibandingkan dengan hasil sandblasting dengan ukuran butir 30 mesh.

\section{Ukuran butir 80 mesh dengan durasi waktu 30, 60, 90 detik.}

Perlakuan sandblasting dengan ukuran butir 80 mesh dengan durasi waktu 30, 60,9 0 detik dihasilkan data pengujian kekerasan Vickers seperti pada Gambar 3.

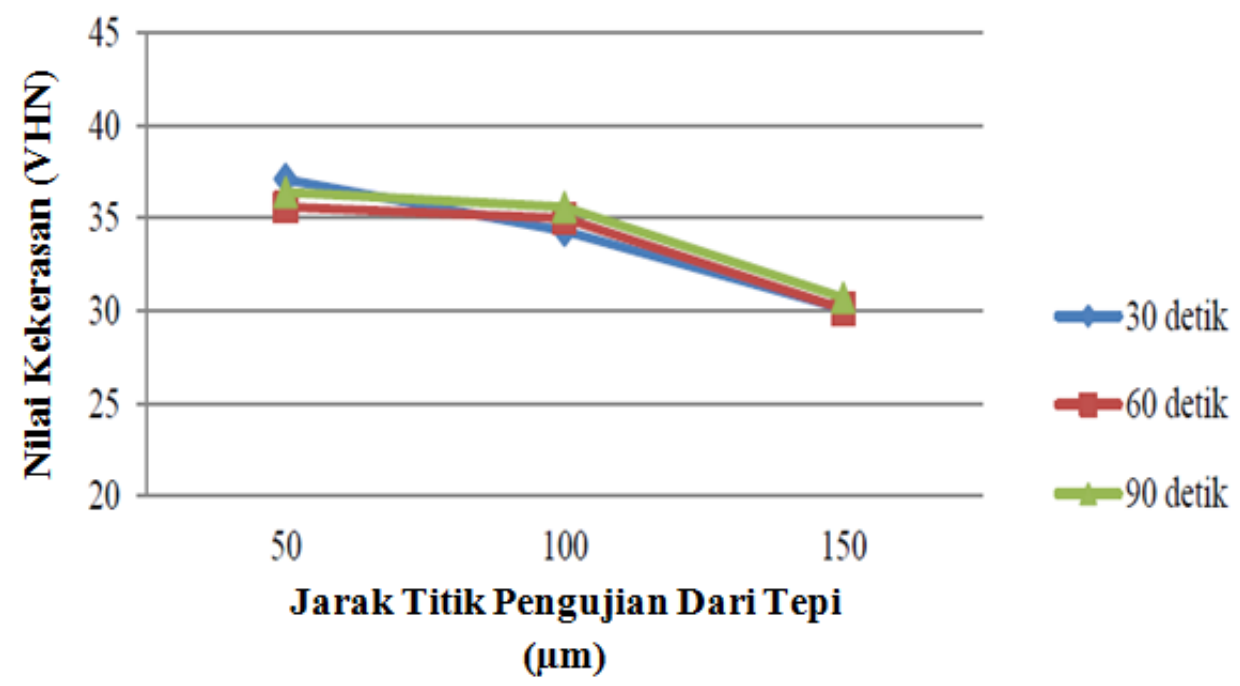

Gambar 3. Kekerasan Vickers pada variasi durasi waktu 30,60,90 detik dengan ukuran butir 80 mesh

Proses sandblasting dengan ukuran butir 80 mesh dengan berbagai variasi durasi waktu ditunjukkan pada Gambar 3. Dari hasil pengujian didapapatkan kenaikan nilai kekerasan yang hampir sama untuk semua variasi waktu dan mengalami penurunan kekerasan seiring dengan jarak dari permukaan, hal ini menunjukkan nilai kekerasan hasil sandblasting untuk ukuran mesh 80 tidak begitu dipengaruhi oleh durasi waktu yang telah ditentukan.

\subsection{Struktur Makro}

Pada Gambar 4, Gambar 5, dan Gambar 6. disajikan foto struktur makro permukaan melintang hasil sandblasting untuk ukuran butir 40,60, dan 80 mesh dengan variasi waktu 30,60, dan 90 detik.

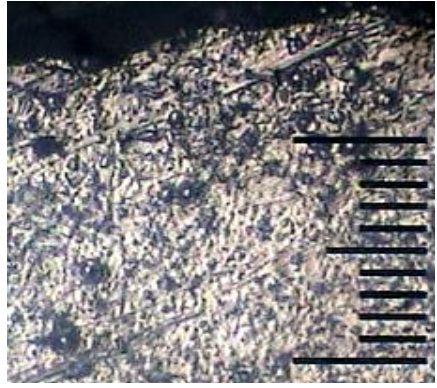

(a)

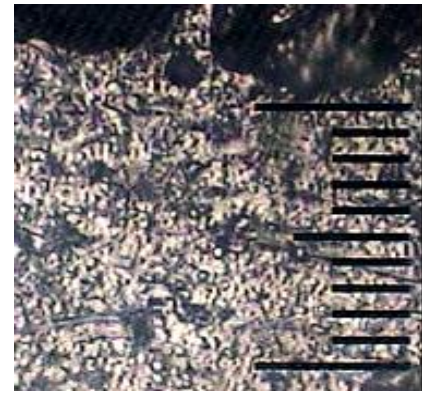

(b)

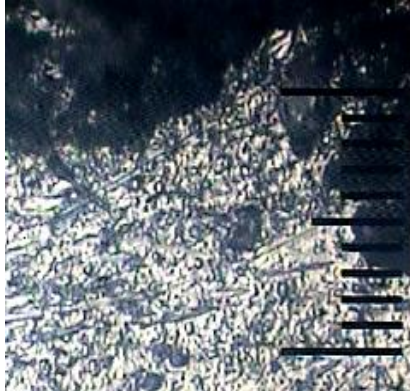

(c )

Gambar 4. Foto struktur makro permukaan melintang material hasil sandblasting dengan pembesaran $200 \mathrm{X}$ (a) 40 mesh 30 detik (b) 40 mesh 60 detik (c) 40 mesh 90 detik 


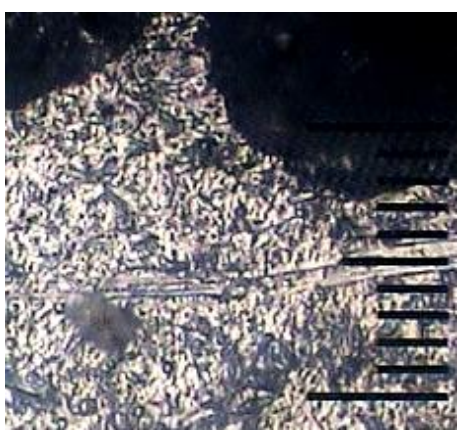

(a)

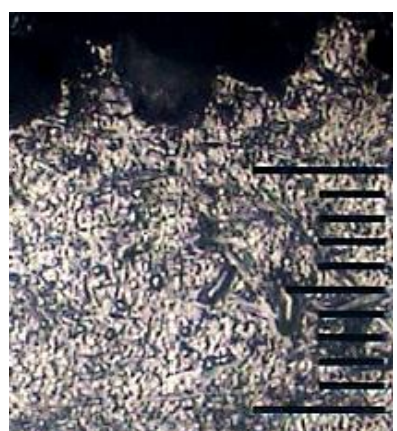

(b)

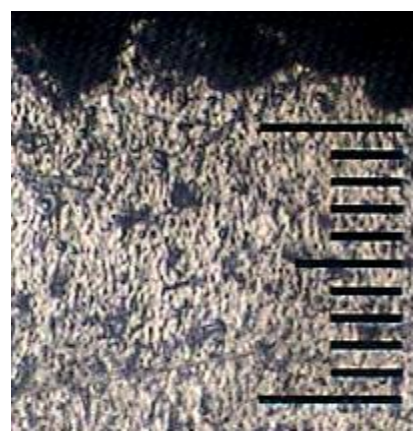

(c)

Gambar 5. Foto struktur makro permukaan melintang material hasil sandblasting dengan pembesaran $200 \mathrm{X}$ (a) 60 mesh 30 detik (b) 60 mesh 60 detik (c) 60 mesh 90 detik

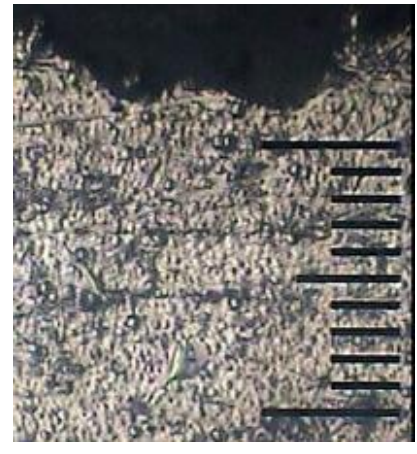

(a)

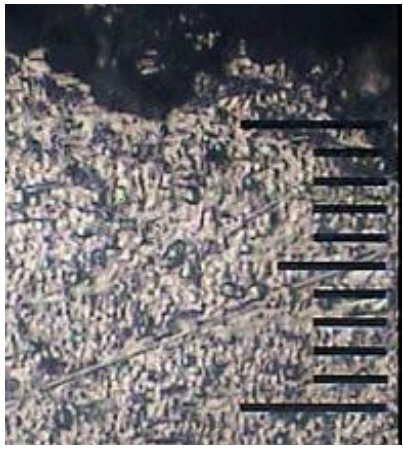

(b)

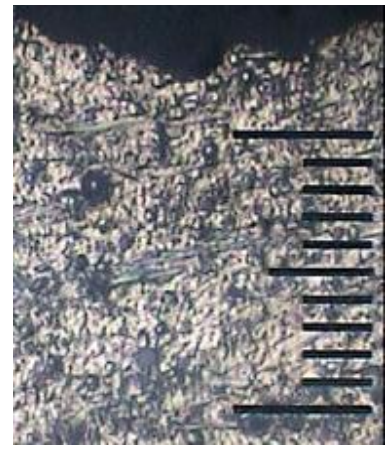

(c)

Gambar 6. Foto struktur makro permukaan melintang material hasil sandblasting dengan pembesaran $200 \mathrm{X}$ (a) 80 mesh 30 detik (b) 80 mesh 60 detik (c) 80 mesh 90 detik

Gambar 4. memperlihatkan bahwa poses sandblasting dengan ukuran butir 40 mesh untuk semua durasi terjadi abrasi pada permukaan material, seiring dengan kenaikan durasi waktu proses sandblasting abrasi yang terjadi dipermukaan material semakin dalam. Gambar 5. menperlihatkan proses sandblasting dengan ukuran butir 60 mesh menunjukkan abrasi terdalam terjadi pada durasi 30 detik dengan bertambahnya durasi proses sandblasting kedalaman semakin berkurang hal ini dikarenakan puncak dari lekukan permukaan dikikis oleh butiran pasir sandblasting pada waktu selanjutnya. Pada Gambar 6. disajikan bentuk permukaan material hasil dari proses sandblasting dengan ukuran butir 80 mesh, untuk semua durasi waktu diperlihatkan kedalaman abrasi yang terjadi relatif sama.

\section{Kesimpulan}

1. Sandblasting dengan variasi durasi 30 detik, 60 detik dan 90 detik di peroleh kekerasan permukaan tertinggi pada besar butir 40 mesh sebesar 39,8 VHN, 60 mesh sebesar 38,6 VHN, 80 mesh sebesar 37,1 VHN. Semakin kecil ukuran mesh butir yang digunakan maka semakin besar peningkatan nilai kekerasan permukaan.

2. Dari hasil foto makro didapatkan abrasi permukaan material yang paling besar terjadi pada ukuran butir 40 mesh. Semakin besar ukuran mesh butir yang digunakan maka semakin kecil abrasi yang terjadi pada permukaan. 


\section{Daftar Pustaka}

[1] Purwanto, H. (2010, January). Pengaruh Pengecoran Ulang Terhadap Kekuatan Tarik Dan Kekerasan Pada Aluminium Cor dengan Cetakan Pasir. In Prosiding Seminar Nasional \& Internasional (Vol. 3, No. 1).

[2] Ahmadi, N., \& Suyitno, S. T. (2014). Pengaruh Deformasi Dingin Dan Surface Mechanical Attrition Treatment (Smat) Terhadap Kekerasan, Struktur Mikro, Dan Ketahanan Korosi Baja Tahan Karat Aisi 316l. (Doctoral dissertation, Universitas Gadjah Mada)

[3] Yaqin, R. I., Iswanto, P. T., Priyambodo, B. H., \& Maliwemu, K. E. U. (2017). Pengaruh durasi shot peening terhadap struktur mikro dan kekerasan permukaan pada AISI 316L. In Seminar Nasional Teknologi Informasi dan Kedirgantaraan (SENATIK) (Vol. 3, pp. 0-4).

[4] Pradana, R. B., \& Kromodiharjo, S. (2017). Studi eksperimen pengaruh tekanan dan waktu sandblasting terhadap kekasaran permukaan, biaya, dan kebersihan pada pelat baja karbon rendah di pt. swadaya graha. Jurnal Teknik ITS, 5(2).

[5] W.P.Bangun, Widiyarta I.M., Purwata I.M. (2017). Pengaruh Waktu dan Ukuran Partikel Dry Sandblasting Terhadap Kekasaran Permukaan Pada Baja Karbon Sedang. Jurnal Teknik Mekanika Unud, 6(1).

[6] Herman, (2014). Pengaruh Shot Peening Terhadap Sifat Mekanis dan Fisis Pada Aluminium Alloy 7075 T65. Teknik Penerbangan Sekolah Tinggi Teknologi Adisucipto, Yogyakarta. 